\title{
EDUCAÇÃO PROFISSIONAL NO BRASIL: REFLEXÕES SOBRE O ENSINO MÉDIO INTEGRADO
}

\section{PROFESSIONAL EDUCATION IN BRAZIL: REFLECTIONS ON THE MEDIUM LEVEL PROFESSIONAL COURSE}

\author{
Priscila de Souza Chisté * \\ Instituto Federal do Espírito Santo - Campus Vitória (*) \\ E-mail: pchiste@ifes.edu.br
}

\section{Resumo}

O artigo em tela apresenta histórico e reflexões sobre a Educação Profissional no Brasil com ênfase no Ensino Médio Integrado. Utiliza como metodologia a pesquisa bibliográfica e documental, pois analisa livros, teses, dissertações, artigos e legislações sobre os assuntos versados. Alerta que existem limites e desafios relacionados à implementação do Ensino Médio Integrado. Contudo, a partir de revisão de literatura, sinaliza como alternativa a formação de professores desde que se considere a educação como um campo multifacetado de tensões, ou seja, sem responsabilizar somente o professor pelo sucesso ou fracasso da prática educativa nessa modalidade de ensino.

Palavras-chave: educação profissional. ensino médio integrado. politecnia. formação humana.

\begin{abstract}
The article presents historical and screen reflections on Professional Education in Brazil with emphasis on medium level professional course. Used as methodology the bibliographical and documentary research, analyzes for books, theses, dissertations, articles and laws on the matters in question. Warns that there are limits and challenges related to implementation of the medium level professional course. However, from literature review, points as an alternative teacher training since it considers education as a multifaceted field of tensions, ie not only blame the teacher for the success or failure of educational practice in this type of education.
\end{abstract}

Keywords: professional education. vocational education. politechnic. human education. 


\section{INTRODUÇÃO}

O artigo em tela apresenta histórico e reflexões relacionados à Educação Profissional no Brasil com ênfase no Ensino Médio Integrado. A metodologia utilizada foi a pesquisa bibliográfica e documental, tendo em vista que utiliza livros, artigos e legislações sobre os assuntos versados. Inicia a seção Percurso da educação profissional: aspectos legais históricos, com a intensão de compreender historicamente a educação profissional e as marcas da dualidade nesta trajetória. Na seção, Caminhos em busca da politecnia, apresenta esse conceito como um dos modos que alguns estudiosos propõem de se romper com a dicotomia entre a educação básica e a técnica e resgatar o princípio da formação humana em sua totalidade.

Já a seção, A integração entre ensino médio e educação profissional, sinaliza que um dos modos de se propor a travessia rumo a politecnia, ou seja, de contemplar o aprofundamento dos conhecimentos científicos produzidos e acumulados historicamente pela sociedade, bem como os objetivos adicionais de formação profissional numa visão da integração dessas dimensões, seria o Ensino Médio Integrado.

Para compreender como essa modalidade de ensino tem sido efetivada na prática, na parte Diálogos com as pesquisas sobre o ensino médio integrado, analisa pesquisas no campo da educação em nível de mestrado e doutorado. Tais investigações apontam os limites e desafios do Ensino Médio Integrado na perspectiva da formação integral/omninateral dos alunos que frequentam essa modalidade de ensino.

Como alternativa para se refletir sobre esta questão, estudiosos propõem que se invista na formação dos professores que atuam no Ensino Médio Integrado para que esses profissionais se apropriem dos pressupostos, da trajetória histórica e dos aspectos legais dessa modalidade de ensino, na perspectiva de propor mudanças na prática pedagógica. Porém, conclui, nas Considerações finais que responsabilizar o professor pelo sucesso ou fracasso do Ensino Médio Integrado seria inconsequente tendo em vista que a educação está envolvida em um campo multifacetado de tensões. 


\section{PERCURSO DA EDUCAÇÃO PROFISSIONAL NO BRASIL: ASPECTOS LEGAIS HISTÓRICOS}

Na história da educação brasileira, a Educação Profissional foi pensada para treinar uma parcela da população para o desempenho de atividades manuais consideradas de nível intelectual inferior, atender às demandas da indústria ou contemplar os grupos sociais desfavorecidos economicamente (CHISTÉ, 2013).

Nessa trajetória, a primeira ação concreta que buscou organizar a aprendizagem de ofícios ocorreu em 1826, quando foi apresentado o Projeto de Lei $^{1}$ sobre a Instrução Pública no Império, que consistia em organizar o ensino público no País, em todos os níveis; fato até então inédito na história da educação brasileira.

Devido à estruturação do ensino no Brasil, ao desenvolvimento industrial e ao aumento da produção manufatureira na primeira metade do século XIX, surgiram os Liceus que eram gerenciados por nobres, fazendeiros, comerciantes e funcionários da burocracia estatal, apoiados também pelos recursos provenientes do Poder Público. O objetivo era amparar os órfãos e, ao mesmo tempo propiciar a oferta da aprendizagem da arte e dos ofícios, rumo a uma mão de obra barata e manipulável. Um dos principais liceus foi o de Artes e Ofícios do Rio de Janeiro (inaugurado em 1858), cujo objetivo era propagar e desenvolver, na classe operária, a instrução indispensável para o exercício racional das artes e ofícios industriais. Os cursos eram gratuitos e vedados aos escravos.

Nessa época, a busca pelo progresso, independência política e pela emancipação econômica baseada na industrialização passou a dominar os debates em torno de um projeto para o País. 0 pensamento industrialista se converteu em medidas educacionais que culminaram no Decreto $\mathrm{n}^{\circ}$ 7.566, de 23 de setembro de 1909, que criou dezenove Escolas de Aprendizes e Artífices, uma em cada Capital dos Estados. Esse novo sistema de Educação Profissional passou a ser mantido pelo Ministério da Agricultura, Comércio e Indústria e tinha como finalidade ofertar à população a

\footnotetext{
${ }^{1} \mathrm{O}$ objetivo desse Projeto de Lei foi estruturar o conjunto dos vários graus de ensino do País, e os estabelecimentos por eles responsáveis estariam divididos em quatro níveis e seriam denominados: pedagogias, destinados ao primeiro grau; liceus, utilizados para o segundo grau; ginásios encarregados de transmitir conhecimentos relativos ao terceiro grau; e, por fim, as academias, responsabilizadas pelo ensino superior (SANTOS, 2000).
} 
Educação Profissional primária e gratuita. A criação das Escolas de Aprendizes Artífices e do ensino agrícola evidenciou um grande passo ao redirecionamento da Educação Profissional no País, pois buscou atender às necessidades emergentes dos empreendimentos nos campos da agricultura e da indústria.

Apesar dos problemas que se apresentavam, como a falta de professores especializados e a alta taxa de evasão, esse modelo de Educação Profissional foi consolidado ao longo do tempo e adquiriu os contornos básicos para a constituição da rede de Escolas Técnicas do País, criadas em 1942.

O processo de industrialização e modernização das relações de produção exigiu um posicionamento mais efetivo das camadas dirigentes com relação à educação nacional. Como parte das respostas a essas demandas, foi criado o Ministério da Educação e da Saúde em 1930, "[...] quando se inicia uma autêntica reestruturação no sistema educacional brasileiro, notadamente no âmbito da Educação Profissional, que, ao instituir a Inspetoria do Ensino Profissional Técnico, ampliou os espaços de consolidação da estrutura do ensino profissional do Brasil" (SANTOS, 2000, p. 216).

Em 1942, o Serviço Nacional de Aprendizagem Industrial (Senai) foi criado pelo governo Vargas em convênio com o setor industrial e representado pela Confederação Nacional da Indústria (CNI). Ele nasceu a partir das demandas da expansão da indústria brasileira, que necessitava de uma formação mínima do operariado, que teria de ser feita de modo rápido e prático. O Senai, sob a direção da CNI, oferecia cursos de curta duração com o objetivo de promover a preparação dos aprendizes menores para se inserirem nas indústrias e cursos de formação continuada para trabalhadores. Com essa ação do governo Vargas, fica revelada a opção governamental de repassar a iniciativa privada a tarefa de preparar a mão de obra para o mundo produtivo. A partir dessa lógica, o ensino secundário e o normal formariam as elites condutoras do País e o profissional, os filhos dos operários, para as artes e os ofícios, ratificando o caráter dualista da educação e sua função reprodutora da estrutura socioeconômica (MOURA, 2007).

Nessa época, foram promulgados diversos decretos-lei para normatizar a educação nacional: as Leis Orgânicas da Educação Nacional. Essas leis evidenciaram a importância da educação dentro do 
País e, em especial, a Educação Profissional, pois foram definidas leis específicas para a formação profissional e para a formação de professores em nível médio. As Leis Orgânicas criaram as Escolas Técnicas Federais.

Em 1948, começou a tramitar no Congresso Nacional o projeto de lei para a elaboração da primeira Lei de Diretrizes e Bases da Educação Nacional (LDB) que entrou em vigor em 1961. Esse período de trâmite e discussões foi rico em debates sobre a sociedade brasileira que estava em conflito entre modelos distintos de desenvolvimento.

A política educacional refletiu esses conflitos de poder, de modo que a luta em torno à criação da LDB ocorreu em meio à polarização de interesses entre os setores populares e populistas que pleiteavam, entre outros aspectos, a extensão da rede escolar gratuita (primário e secundário); e equivalência entre Ensino Médio propedêutico e profissionalizante, com possibilidade de transferência de um para outro (BRASIL, 2007, p. 13).

Outra inovação da LDB de 1961 foi estender ao Senai a possibilidade de instituir a mesma organização que estava prevista no sistema público de ensino: "Assim sendo, o Senai poderia oferecer o curso ginasial em quatro anos e o curso técnico industrial em três anos equivalente ao curso secundário, o que facultava aos alunos dessa instituição ingressar em qualquer curso de nível superior" (SANTOS, 2000, p. 219). Contudo, Ciavatta (2005) alerta que essa equivalência de disciplinas do ensino técnico e do acadêmico se iniciou com as Leis de Equivalência nos anos de 1950, alcançou plena equivalência com a LBD n 3.204/1961 e não era só prioridade do Senai.

Portanto, a primeira LDB proporcionou a liberdade de atuação da iniciativa privada no domínio educacional e também deu plena equivalência a todos os cursos do mesmo nível sem a necessidade de exames e provas de conhecimento, visando à equiparação. Esse fato colocou, formalmente, um fim na dualidade de ensino.

Essa dualidade só acabou formalmente porque os currículos se encarregaram de mantê-la, uma vez que a vertente do ensino voltada para a continuidade de estudos em nível superior e, portanto, destinada às elites, continuava a privilegiar os conteúdos que eram exigidos nos 
processos seletivos de acesso à educação superior, ou seja, as Ciências, as Letras e as Artes. Enquanto isso, nos cursos profissionalizantes, esses conteúdos eram reduzidos em favor das necessidades imediatas do mercado de trabalho.

Cabe observar que as pressões geradas pelo Milagre Econômico (1969 a 1971) impulsionaram ainda mais o chamado para a formação profissional, que teve como uma de suas implicações a regulamentação, em 1968, da profissão de técnico de nível médio. A partir dos acordos entre o governo brasileiro e o United States Aid Internacional Development (Usaid), ampliaram-se as matrículas nos cursos técnicos, o que provocou uma aceleração da formação dos trabalhadores nos moldes exigidos pela divisão internacional do trabalho. Frigotto, Ciavatta e Ramos (2005, p. 33) apontam que, com o aumento da procura de empregos, acarretado inclusive pela rápida urbanização, "[...] os empregadores passaram a exigir o nível de escolaridade cada vez maior como modo de seleção preliminar. Com isto, cresceu a demanda pelo Ensino Superior, cuja pressão levou à reforma universitária realizada em 1968".

Assim, em 1971, sob o governo militar, ocorreu uma profunda reforma da educação básica pela Lei $\mathrm{n}^{\circ}$ 5.692/71 - Lei da Reforma de Ensino de 1ㅇ e 20 Graus - que promoveu a obrigatoriedade da Educação Profissional de nível médio. Frigotto, Ciavatta e Ramos (2005) consideram que essa lei apresentou um duplo propósito: o de atender à demanda por técnicos de nível médio e o de conter a pressão sobre o Ensino Superior. Segundo os autores, o discurso utilizado para sustentar o caráter manifesto de formar técnicos construiu-se sob o argumento da escassez de técnicos no mercado e da necessidade de evitar a frustração de jovens que não ingressavam nas universidades nem no mercado por não apresentar uma habilitação profissional.

O Documento-Base para a Educação Profissional Técnica de Nível Médio Integrada ao Ensino Médio (BRASIL, 2007) aponta ainda que a profissionalização obrigatória do ensino de 20 grau foi uma resposta diferente às demandas educacionais das classes populares. Ela garantiria a inserção dos concludentes dos cursos técnicos no mercado de trabalho em plena expansão econômica, devido aos elevados índices de desenvolvimento.

Entretanto, na prática, a compulsoriedade se restringiu, em grande parte, ao âmbito público, notadamente nos sistemas de ensino dos Estados e no federal. Enquanto isso, as escolas privadas 
continuaram com os currículos propedêuticos voltados para as Ciências, Letras e Artes e visavam ao atendimento às elites.

Nos sistemas estaduais de ensino, a profissionalização compulsória foi amplamente problemática e não foi implantada completamente. Em primeiro lugar, porque a concepção curricular que emanava da lei empobrecia a formação geral do estudante em favor de uma profissionalização instrumental para o mercado de trabalho, sob a alegação da importância da relação entre teoria e prática para a formação integral do indivíduo.

No entanto, de forma incoerente com o discurso, ao invés de se ampliar a duração do 2o grau para incluir os conteúdos da formação profissional de forma integrada aos conhecimentos das Ciências, das Letras e das Artes, o que houve foi a redução dos últimos em favor dos primeiros, os quais assumiram um caráter instrumental e de baixa complexidade (BRASIL, 2007). Isso não ocorreu por acaso, pois fazia parte da própria concepção de desenvolvimento do País e da reforma educacional em questão.

Diante desse quadro, observou-se um acentuado movimento dos filhos da classe média das escolas públicas para as privadas na busca de garantir uma formação que lhes permitisse continuar os estudos no nível superior.

Em 1982, de modo antagônico à ideia da compulsoriedade, ocorreu a promulgação da Lei $n^{\circ} 7.044$, que extinguiu a profissionalização obrigatória no $2^{\circ}$ grau. $O$ dualismo nesse momento se difere do período anterior à LDB de 1961, já que ocorreu preservando a equivalência entre os cursos propedêuticos e técnicos. De acordo com Ciavatta, Frigotto e Ramos (2005, p. 34), a marca do dualismo não estava mais na impossibilidade de os alunos dos cursos técnicos ingressarem no Ensino Superior, mas sim no plano dos valores e dos conteúdos da formação. 
No primeiro caso, o ideário social mantinha o preceito de que o Ensino Médio técnico destinava-se aos filhos das classes trabalhadoras cujo horizonte era o mercado de trabalho, e não o Ensino Superior. No segundo caso, enquanto a Lei $\mathrm{n}$. 5.692/71 determinava que na carga horária mínima prevista para o ensino técnico de $2^{\circ}$ grau (2.200 horas) houvesse a predominância da parte especial em relação à geral, a Lei n. 7.044/82, ao extinguir a profissionalização compulsória, considerou que nos cursos não profissionalizantes as $\mathbf{2 . 2 0 0}$ horas pudessem ser totalmente destinadas à formação geral. Com isto, os estudantes que cursavam o ensino técnico ficavam privados de uma formação básica plena, que por sua vez, predominava nos cursos propedêuticos, dando, àqueles que cursavam esses cursos vantagens em relação às condições de acesso ao Ensino Superior e à cultura em geral.

No caso das Escolas Técnicas Federais, a inflexão promovida pela Lei $n^{\circ} 7.044 / 82$ voltou a valorizar a formação por elas desenvolvida, já que essas seriam as instituições mais adequadas para conferir ao então $2^{\circ}$ grau o caráter profissionalizante, voltado para a formação em habilitações profissionais específicas. Pode-se dizer, então, que, a partir dessa lei, até o final da década de 1980, as Escolas Técnicas Federais desempenharam a função de formar técnicos de $2^{\circ}$ grau com qualidade, sendo reconhecidas pela sociedade civil pelo grau de excelência de seus cursos. Contudo, oportunizavam pouco contato com as disciplinas propedêuticas, o que impulsionou a busca, por aqueles que queriam chegar ao Ensino Superior, pelos pré-vestibulares.

Contudo, na década de 1980, a preparação do pré-vestibular não assegurava o acesso ao Ensino Superior público, porque poucos cursos eram oferecidos no turno noturno nas universidades. Isso dificultava ainda mais o acesso ao curso superior por parte daqueles que tinham que trabalhar. Aos poucos foram surgindo cursos noturnos, mas existia, por parte dos professores, da universidade e dos próprios alunos, um certo preconceito que chega a casos extremos, por exemplo, a fala de professores que diziam que os cursos noturnos não deveriam existir porque os alunos que 0 frequentam não conseguem se dedicar o suficiente. Atualmente, grande parte da demanda pelo Ensino Superior noturno tem sido preenchida pelas faculdades particulares. Porém, amplas são as discussões sobre a qualidade do ensino nessas instituições. 
Com a instalação da Constituinte (1987), fechou-se o ciclo da ditadura civil-militar. Nesse sentido, a sociedade, representada por entidades educacionais e científicas, mobilizou-se fortemente pela incorporação do direito à educação pública, laica, democrática e gratuita. A seguir, apresentaremos essa discussão na perspectiva de introduzir as discussões a cerca da politecnia e da criação do Ensino Médio Integrado.

\section{CAMINHOS EM BUSCA DA POLITECNIA}

Frigotto, Ciavatta e Ramos (2005) comentam que a partir da Constituinte de 1987 se travaram debates teóricos entre aqueles que investigavam a relação entre o trabalho e a educação e afirmavam ser necessária a vinculação da educação à prática social e o trabalho como princípio educativo. Sobre essa questão, pontuam que:

Se o saber tem uma autonomia relativa face ao processo de trabalho do qual se origina, o papel do Ensino Médio deveria ser o de recuperar a relação entre conhecimento e a prática do trabalho. Isto significaria explicitar como a ciência se converte em potência material no processo de produção. Assim, seu horizonte deveria ser o de propiciar aos alunos o domínio dos fundamentos das técnicas diversificadas utilizadas na produção, e não o mero adestramento em técnicas produtivas. Não se deveria, então, propor que o Ensino Médio formasse técnicos especializados, mas sim politécnicos (FRIGOTTO; CIAVATTA; RAMOS, 2005, p. 35).

Para compreender essa discussão, a categoria Politecnia precisa ser explorada de modo mais aprofundado. Politecnia diz respeito ao "[...] domínio dos fundamentos científicos das diferentes técnicas que caracterizam o processo de trabalho moderno" (SAVIANI, 2003, p. 140). Assim, o Ensino Médio deveria se concentrar nas modalidades fundamentais que dão base à multiplicidade de processos e técnicas de produção existentes. O ideário da Politecnia busca romper com a dicotomia entre a educação básica e a técnica e resgatar o princípio da formação humana em sua totalidade. Em termos epistemológicos e pedagógicos, esse ideário defendia um ensino que integrasse ciência e cultura, humanismo e tecnologia. Visa ao desenvolvimento de todas as potencialidades humanas. 
Por essa perspectiva, o objetivo profissionalizante não teria um fim em si mesmo nem se pautaria pelos interesses do mercado, mas constituir-se-ia numa possibilidade a mais para os estudantes na construção de seus projetos de vida, socialmente determinados, possibilitados por uma formação ampla e integral (CIAVATTA; FRIGOTTO; RAMOS, 2005, p. 36).

Na sociedade capitalista, a escola profissional significa, correntemente, uma escola de categoria inferior destinada aos jovens desprovidos de recursos, corroborando a diferenciação social (MACHADO, 1991). De modo contrário, na escola do trabalho socialista, os conhecimentos técnicos e práticos têm um nível de compreensão intelectual que visa a promover as condições para a supressão dos mecanismos reprodutores da desigualdade cultural e social. Essa escola, segundo a autora, teria por objetivo ser mais que um vínculo de difusão dos novos princípios sociais. Ela se caracterizaria "[...] como uma influência organizada do proletariado sobre as demais classes, com o intuito de criar as novas gerações, capazes de promover o prosseguimento da revolução até a completa transformação da sociedade" (MACHADO, 1991, p. 152).

A escola politécnica não é aquela "[...] onde se estudam muitos ofícios, mas onde se ensina às crianças a compreender a essência dos processos de trabalho, a substância da atividade laboriosa do povo e as condições de êxito no trabalho. É uma escola onde as crianças aprendem a medir a extensão de suas faculdades" (MACHADO, 1991, p.156). Nesse sentido, o ensino politécnico é aquele destinado a desenvolver uma cultura geral do trabalho, o que pressupõe a compreensão da produção em seu conjunto, o conhecimento da direção em que se desenvolvem a técnica e as mudanças tecnológicas e de atividade. Além disso, "[...] a cultura geral do trabalho envolve a compreensão não só da organização de um trabalho particular, como o da fábrica, mas a organização do trabalho em geral referente a todo o conjunto da sociedade" (MACHADO, 1991, p. 156).

No plano pedagógico, esta proposta de articulação entre o trabalho e o ensino pressupõe a integração de todas as disciplinas, saturando-as, ao máximo, com as questões e desafios concretos suscitados pela atividade laborativa. Essa forma de integração tem por objetivo, no seu limite, romper com a fragmentação do conhecimento. Pressupõe perguntar como se articula a educação para o trabalho com o ensino das demais matérias, o que permite descobrir se se trata de 
formação politécnica ou de uma pequena atividade artesanal ou, ainda, da simples manipulação desprovida de objetivo, de um instrumento qualquer. A formação politécnica deve penetrar todas as matérias e deve traduzir-se na escolha do ensino tanto da Física como da Química, tanto das Ciências Naturais como das Ciências Sociais. "É necessário articular mutuamente as distintas matérias; é necessário articulá-las com a atividade prática e em especial com a formação do trabalho. Só com esta articulação, a formação para o trabalho pode se revestir do caráter politécnico" (MACHADO, 1991, p.156).

Nesse sentido, a partir das ideias de Bloski, Machado compreende que as disciplinas do currículo tradicional devem passar por reestruturação, tendo em vista o ensino com base na realidade concreta. O aluno deve estudar o mundo e a vida e não disciplinas específicas, pois quem educa e forma é a vida. Por conseguinte, na escola, deve-se fazer ativamente presente a vida em sua plenitude. Mas a vida não pode dividir-se em distintas matérias. As grandes unidades da vida, como a economia e a vida social, não se oferecem aos educandos como se fossem "matérias", senão como unidades, totalidades, temas ou complexos: "O ensino, no seu sentido estrito, deve sempre partir do domínio da vida e não de um objeto" (MACHADO, 1991, p. 158). As ideias de Machado apontam a necessidade de problematizar e romper com o currículo sistematizado pela via de matrizes curriculares fragmentadas.

Assim, a escola politécnica visa a pôr o aluno em contato com a herança cultural e ser uma escola criadora, capaz de desenvolver sua personalidade e autonomia. Uma escola cujo objetivo básico é desenvolver o alicerce cultural sólido e durável, capaz de acompanhar o indivíduo pela sua vida, útil às suas atividades de trabalho e de vida, independentemente da especificidade exercida. Concomitantemente ao furor das discussões, elaboradas por alguns intelectuais brasileiros e internacionais influenciados pela tradição marxista e suas implicações na educação nos anos de 1989 e 1990, ocorre, no Congresso Nacional, o processo que culmina com criação de uma nova LDB, a Lei no 9.394/1996, elaborada nos moldes do ideário neoliberal.

Nessa época, já quase não há mais 2o grau profissionalizante no País, exceto nas Escolas Técnicas Federais, Escolas Agrotécnicas Federais e em poucos sistemas estaduais de ensino. Importante colocar que, em 1994, a Lei n 8.948 dispõe que as Escolas Técnicas Federais e as Escolas Agrotécnicas Federais sejam transformadas em Centros Federais de Educação Tecnológica. 
Mediante decreto específico de cada instituição e em função de critérios estabelecidos pelo Ministério da Educação, os centros recebiam os recursos humanos e financeiros necessários para os seus funcionamentos.

A LDB de 1996 dispõe a Educação Profissional num capítulo separado da educação básica e buscou, em tese, superar os enfoques assistencialistas e o preconceito social contido nas primeiras leis relacionadas com a Educação Profissional do País. Contudo, essa LDB é ambígua e minimalista no que se refere ao Ensino Médio e à Educação Profissional. Ela estrutura a educação regular em dois níveis, a educação básica e a educação superior, mas coloca a Educação Profissional em outro capítulo constituído por três artigos.

Dois trechos explicitam o caráter minimalista e ambíguo dessa lei: o $\S 2^{\circ}$ do art. 36 , que estabelece que o Ensino Médio poderá preparar para o exercício de profissões técnicas, e o art. 40, que coloca que a Educação Profissional será desenvolvida em articulação com o ensino regular ou por diferentes estratégias de educação continuada, em instituições especializadas ou no ambiente de trabalho. Tais trechos evidenciam que quaisquer articulações entre o Ensino Médio e a Educação Profissional são possíveis, assim como a completa desarticulação entre os dois. De acordo com Moura (2007, p. 9), essa redação não é inocente, nem desinteressada. Ao contrário, “[...] tem o fim de permitir a separação entre as duas ofertas, o que já era objeto de Projeto de Lei do executivo (PL 1603/96), que tramitava no Congresso Nacional antes da promulgação da LDB". Segundo o autor, tal projeto de lei foi absorvido pelo Decreto $n^{\circ} 2.208 / 1997$.

Assim, em 1997, com o Decreto $n^{\circ} 2.208$ e o Programa de Expansão da Educação Profissional (Proep), inicia-se mais uma reforma na Educação Profissional. A fim de financiar a reforma - parte integrante do projeto de privatização do Estado em atendimento à política neoliberal -, "[...] o governo FHC negocia empréstimo junto ao Banco Interamericano de Desenvolvimento (BID), materializado por meio do PROEP" (MOURA, 2007, p. 9).

Nesse contexto, o Ensino Médio retoma legalmente um sentido puramente propedêutico, enquanto os cursos técnicos, agora obrigatoriamente separados do Ensino Médio, passam a ser oferecidos de duas formas: concomitante e subsequente. Além disso, o decreto prevê o nível tecnológico que dá formação superior, tanto graduação como pós-graduação, a jovens e adultos. 
Quanto ao currículo, prevê que a Educação Profissional de nível técnico tenha organização curricular própria, independente do currículo do Ensino Médio. Assim sendo, essa modalidade de Educação Profissional será sempre concomitante ou posterior à conclusão do Ensino Médio, mas mantém, contudo, vínculo de complementaridade. Esse decreto reforçou a dicotomia entre o fazer e o pensar, uma vez que impediu a existência dos cursos de nível médio que tinham matriz curricular composta por disciplinas técnicas e de conteúdo geral. Dessa forma, longe de significar a construção de uma escola única, capaz de superar a dualidade da formação humana, o Ensino Médio e a Educação Profissional desencadeados a partir da década de 1990, reafirmaram o desinteresse pela formação humana.

\section{A INTEGRAÇÃO ENTRE ENSINO MÉDIO E EDUCAÇÃO PROFISSIONAL}

Com o fim do governo de Fernando Henrique Cardoso, em janeiro de 2003, uma nova chance para a integração entre o Ensino Médio e a Educação Profissional aconteceu pela via da publicação do Decreto $n^{\circ} 5.154 / 2004$, incorporado à LDB $n^{\circ} 9.394 / 1996$ por meio da Lei $n^{\circ} 11.741 / 2008$. A discussão sobre as leis anteriores resultou em uma significativa mobilização dos setores educacionais vinculados ao campo da Educação Profissional, principalmente no âmbito dos sindicatos e dos pesquisadores da área trabalho e educação. Desse modo, durante o ano de 2003 e até julho de 2004, houve grande efervescência nos debates relativos à relação entre o Ensino Médio e a Educação Profissional.

Assim, retoma-se a discussão sobre a educação politécnica, compreendendo-a como uma educação unitária e universal destinada à superação da dualidade entre cultura geral e cultura técnica e voltada para "[...] o domínio dos conhecimentos científicos das diferentes técnicas que caracterizam o processo de trabalho produtivo moderno" (SAVIANI, apud FRIGOTTO; CIAVATTA; RAMOS, 2005, p. 42) sem formar profissionais em cursos técnicos específicos. De acordo com Ramos (2008), a educação politécnica é aquela que busca, a partir do desenvolvimento do capitalismo e de sua crítica, superar a proposta burguesa de educação que potencialize a transformação estrutural da realidade. 
Nessa perspectiva, a escolha por uma formação profissional específica em nível universitário ou não só viria após a conclusão da educação básica de caráter politécnico. Entretanto, essa retomada produz reflexões importantes quanto à possibilidade material da implementação, hoje, da politecnia na educação básica brasileira, na perspectiva aqui mencionada.

Tais reflexões e análises permitiram concluir que as características atuais da sociedade brasileira dificultam a implementação da politecnia ou educação tecnológica em seu sentido pleno, uma vez que, dentre outros aspectos, a extrema desigualdade socioeconômica obriga grande parte dos filhos da classe trabalhadora a buscar a inserção no mundo do trabalho visando a complementar o rendimento familiar ou mesmo a auto-sustentação muito antes dos 18 anos de idade (BRASIL, 2007, p. 23).

Nesse sentido, a tentativa de implementar a politecnia de forma universal e unitária não encontraria uma base material concreta de sustentação na sociedade brasileira atual, uma vez que esses jovens não poderiam se dar o luxo de esperar até os vinte anos ou mais para iniciar a trabalhar. Tais reflexões conduziram ao entendimento de que uma solução transitória e viável seria um tipo de Ensino Médio que garantisse a integralidade da educação básica, ou seja, que contemplasse o aprofundamento dos conhecimentos científicos produzidos e acumulados historicamente pela sociedade, como também os objetivos adicionais de formação profissional numa visão da integração dessas dimensões. Essa perspectiva, ao adotar a ciência, a tecnologia, a cultura e o trabalho como eixos estruturantes, contemplaria as bases em que se pode desenvolver uma educação tecnológica ou politécnica e, ao mesmo tempo, uma formação profissional exigida pela dura realidade socioeconômica do País. "O Ensino Médio integrado ao ensino técnico, sob uma base unitária de formação geral, é uma condição necessária para se fazer a travessia para uma nova realidade" (FRIGOTTO; CIAVATTA; RAMOS, 2005, p. 43).

Foi a partir dessa discussão que se edificaram as bases que deram origem ao Decreto $n^{\circ}$ 5.154/2004. Esse instrumento legal, além de manter as ofertas dos cursos técnicos concomitantes e subsequentes por meio do Decreto $n^{\circ} 2.208 / 1997$, teve o grande mérito de revogá-lo e de trazer de volta a possibilidade de integrar o Ensino Médio à Educação Profissional, agora, numa 
perspectiva que não se confunde totalmente com a educação politécnica, mas que aponta em sua direção porque contém os princípios de sua construção.

O reestabelecimento dessa garantia por meio do Decreto $n^{\circ} 5.154 / 2004$, pretende reinstaurar um novo ponto de partida para essa travessia, de tal forma que o horizonte do Ensino Médio seja a consolidação da formação básica unitária e politécnica, centrada no trabalho, na ciência e na cultura, numa relação mediada com a formação profissional específica que se consolida em outros níveis e modalidades de ensino (RAMOS, 2008, p. 15).

O Decreto $n^{\circ} 5.154 / 2004$ prevê no art. $4^{\circ}$, que a Educação Profissional técnica de nível médio seja desenvolvida de forma articulada com o Ensino Médio. Porém, o $\S 1^{\circ}$ desse artigo coloca que a articulação entre a Educação Profissional técnica de nível médio e o Ensino Médio deve acontecer de forma integrada, oferecida somente a quem já tenha concluído o Ensino Fundamental. O curso deve ser planejado de modo a conduzir o aluno à habilitação profissional técnica de nível médio, na mesma instituição de ensino, contando com matrícula única para cada aluno, ou de forma concomitante, oferecida somente a quem já tenha concluído o Ensino Fundamental ou que esteja cursando o Ensino Médio. O concomitante pressupõe a existência de matrículas distintas para cada curso e pode se efetivar na mesma instituição de ensino, aproveitando-se as oportunidades educacionais disponíveis, ou em instituições de ensino distintas. Além disso, pode ocorrer de forma subsequente, oferecida somente a quem já tenha concluído o Ensino Médio. Como dissemos, esses aspectos revelam uma continuidade em algumas das ações propostas pelo Decreto $n^{\circ} 2.208,1997$.

Outro documento importante que aborda o Ensino Médio Integrado é o Parecer CNE/CEB no 39/2004. ${ }^{2}$ Tal documento trata da Aplicação do Decreto $n^{\circ} 5.154 / 2004$ e coloca que a Educação Profissional não está no lugar do Ensino Médio, mas é uma possibilidade para o aluno matriculado ou egresso do Ensino Fundamental, Médio e Superior. É também uma oportunidade para o trabalhador em geral jovem ou adulto que será desenvolvida em articulação com o ensino regular

\footnotetext{
${ }^{2}$ Ciavatta (2005) alerta que, apesar dos avanços, o Parecer no 39/2004 mantém o espírito do Decreto № 2.208/1997, pois conserva os conceitos dos documentos do governo Fernando Henrique Cardoso como competências para o mercado.
} 
ou por diferentes estratégias de educação continuada, em instituições especializadas ou no ambiente de trabalho.

O Parecer aponta como palavra-chave a Articulação, vista como uma nova forma de relacionamento entre a Educação Profissional e o Ensino Médio. Alerta que é preciso oportunizar uma carga horária mínima de 800 horas por ano para o Ensino Médio. Além disso, o Ensino Médio Integrado necessita ser visto como um curso único, nos termos de um projeto pedagógico que ofereça e garanta os componentes curriculares simultaneamente, desde o início até a conclusão do curso.

Nesse sentido, o Ensino Médio é a sustentação indispensável para a Educação Integrada dos jovens, com um tratamento curricular integrado que garanta isso tudo de forma sincrônica. Portanto, a carga horária de três a quatro anos não é a somatória de dois cursos distintos entre conhecimentos e suas aplicações, numa dicotomia entre teoria e prática. O curso de Educação Profissional Técnica de Nível Médio, realizado na forma integrada com o Ensino Médio, deve ser considerado como um curso único desde a sua concepção plenamente integrada e ser desenvolvido como tal, desde o primeiro dia até o último. Todos os componentes curriculares devem receber tratamento integrado, nos termos do projeto pedagógico da instituição de ensino. Nesse sentido, os planos de curso devem ser aprovados pelo órgão próprio do respectivo sistema de ensino e a organização curricular sistematizada em disciplinas, projetos ou núcleos temáticos.

Para Ciavatta (2005, p. 84), é preciso buscar as origens do termo integrar a partir das ideias de Gramsci, com um

[...] sentido de completude, de compreensão das partes no seu todo ou da unidade no diverso, de tratar a educação como totalidade social, isto é, nas múltiplas mediações históricas que concretizam os processos educativos [...] queremos que a educação geral se torne inseparável da Educação Profissional em todos os campos onde se dá a preparação para o trabalho: seja nos processos produtivos, seja nos processos educativos como a formação inicial, como o ensino técnico, tecnológico ou superior. Significa que buscamos enfocar o trabalho como princípio educativo, no sentido de superar a dicotomia trabalho manual/trabalho 
intelectual, de incorporar a dimensão intelectual ao trabalho produtivo, de formar trabalhadores capazes de atuar como dirigentes e cidadãos.

Segundo o Documento-Base para a Educação Profissional Técnica de Nível Médio Integrada ao Ensino Médio (BRASIL, 2007), o sentido de integração expressa uma concepção de formação humana, com base na integração de todas as dimensões da vida no processo educativo, e visa à formação omnilateral dos sujeitos.

Essas dimensões são o trabalho, a ciência e a cultura. O trabalho compreendido como realização humana inerente ao ser (sentido ontológico) e como prática econômica (sentido associado ao modo de produção); a ciência compreendida como os conhecimentos produzidos pela humanidade que possibilita o contraditório avanço das forças produtivas; e a cultura, que corresponde aos valores éticos e estéticos que orientam as normas de conduta de uma sociedade (BRASIL, 2007, p. 40-41).

Para Manacorda (1991), em frente à realidade da alienação humana, na qual todo homem, alienado por outro, está alienado da própria natureza, e o desenvolvimento positivo está alienado de uma esfera restrita, está a exigência da omnilateralidade. A omnilateralidade refere-se a um desenvolvimento total, completo, multilateral, em todos os sentidos das faculdades e das forças produtivas, das necessidades e da capacidade da sua satisfação. Segundo esse autor, Marx nos Manuscritos de 1844, utiliza pela primeira vez a expressão omnilateral quando diz que "[...] o homem se apropria de uma maneira omnilateral do seu ser omnilateral, portanto como ser total" (MARX, 2004, p. 108). Nesse sentido, omnilateralidade é, portanto, a chegada histórica do homem a uma totalidade de capacidades produtivas e, ao mesmo tempo, a uma totalidade de capacidades de consumo e prazeres, em que se deve considerar sobretudo o gozo daqueles bens espirituais, além dos materiais, e dos quais o trabalhador tem estado excluído em consequência da divisão do trabalho. A divisão do trabalho é reforçada pela escola. Ela também é causadora da unilateralidade, pois não abrange, muitas vezes, a problemática da interação entre a escola e a sociedade. 
Segundo Manacorda (1991), o homem omnilateral é educado com doutrinas não ociosas, com ocupações não estúpidas, capaz de livrar-se da estreita esfera de um trabalho dividido. Ele é resultado de um processo histórico de autocriação. É o ser que se apropria de uma totalidade de forças produtivas objetivamente existentes, interiorizando-as para, a seguir, exteriorizá-las por meio de suas faculdades criativas.

A partir dessas bases, Ramos (2005) aponta ser necessário criar um projeto de Ensino Médio que tenha como eixo o trabalho, a ciência e a cultura. Um projeto que garanta ao jovem o direito a uma formação completa para a leitura de mundo e para a atuação crítica integrada à sua sociedade política. Essa formação supõe a compreensão das relações sociais subjacentes a todos os fenômenos (CIAVATTA, 2005), com a compreensão de que os homens e mulheres são seres histórico-sociais que atuam no mundo concreto para satisfazer suas necessidades subjetivas e sociais e, nessa ação, produzem conhecimentos.

Assim, a história da humanidade é a história da produção da existência humana e a história do conhecimento é a história do processo de apropriação social dos potenciais da natureza para o próprio homem, mediada pelo trabalho. Por isso, o trabalho é mediação ontológica e histórica na produção de conhecimento (BRASIL, 2007, p. 42).

O princípio é de que o trabalho é mediação entre o homem e o objeto a ser investigado/conhecido e que a apropriação social do conhecimento assim produzido é o que confere significado a uma escola que se diz como ativa e criadora. "Ter o trabalho como princípio educativo implica referir-se a uma formação baseada no processo histórico e ontológico de produção da existência humana, em que a produção do conhecimento científico é uma dimensão" (RAMOS, 2005, p. 119).

Ciavatta (2005) alerta que, apenas ao enfocar o trabalho na sua particularidade histórica, nas mediações específicas que Ihe dão forma e sentido no tempo e no espaço, podemos apreendê-lo ou apreender o mundo do trabalho na sua historicidade, como atividade criadora. Porém, de modo contrário, na sociedade atual, o trabalho pode ser penoso, capaz de alienar o ser humano de si mesmo, dos outros e dos produtos de seu trabalho na forma de mercadoria. 
Ligado a isso, faz-se necessário considerar que a realidade concreta é uma totalidade, síntese de múltiplas relações: "[...] a possibilidade de conhecer a totalidade a partir das partes é dada pela possibilidade de se identificar os fatos ou conjunto de fatos que deponham mais sobre a essência do real; e, ainda, de distinguir o essencial do assessório, assim como o sentido objetivo dos fatos" (RAMOS, 2005, p. 119). Desse modo, a totalidade significa um todo estruturado e dialético, do qual ou no qual um fato, ou conjunto de fatos, pode ser compreendido pela determinação das relações que os constituem.

Ramos (2005) considera necessário integrar todas as dimensões da vida no processo educativo, pois o trabalho, a ciência e a cultura são categorias indissociáveis da formação humana. Essa concepção de trabalho associa-se à concepção de ciência, pois relaciona-se com conhecimentos produzidos, sistematizados e legitimados socialmente ao longo da história, como resultado de um processo empreendido pela humanidade na busca da compreensão e transformação dos fenômenos naturais e sociais (RAMOS, 2005). Portanto, a ciência conforma conceitos e métodos que são transmitidos para diferentes gerações, e, ao mesmo tempo, podem ser questionados e superados historicamente, no movimento permanente de construção de novos conhecimentos.

De acordo com o Documento-Base citado anteriormente (BRASIL, 2007), o conhecimento é uma produção do pensamento pela qual se apreendem e se representam as relações que constituem e estruturam a realidade.

Apreender e determinar essas relações exige um método, que parte do concreto empírico - forma como a realidade se manifesta - e, mediante uma determinação mais precisa através da análise, chega a relações gerais que são determinantes do fenômeno estudado. A compreensão do real como totalidade exige que se conheçam as partes e as relações entre elas, o que nos leva a constituir seções tematizadas da realidade. Quando essas relações são 'arrancadas' de seu contexto originário e mediatamente ordenadas, tem-se a teoria. A teoria, então, é o real elevado ao plano do pensamento. Sendo assim, qualquer fenômeno que sempre existiu como força natural só se constituiu em conhecimento quando o ser humano dela se apropria tornando-a força produtiva para si (BRASIL, 2007, p. 43). 
Como exemplo, o referido documento traz a descarga elétrica, os raios, a eletricidade estática como os fenômenos naturais que sempre existiram, mas que não se constituíram como conhecimento enquanto o ser humano não se apropriou desses fenômenos conceitualmente, formulando teorias que potencializassem o avanço das forças produtivas.

A outra dimensão da vida que precisa integrar o processo educativo é a cultura. Segundo Ramos (2005), a cultura deve ser entendida como diferentes formas de criação da sociedade, seus valores, suas normas de conduta, suas obras. Portanto, a cultura é tanto a produção ética quanto a estética de uma sociedade. Assim se pode compreender que os conhecimentos característicos de um tempo histórico e de um grupo social trazem a marca das razões, dos problemas, das necessidades e das possibilidades que motivaram o avanço do conhecimento em uma sociedade.

O Documento-Base para a Educação Profissional Técnica de Nível Médio Integrada ao Ensino Médio (BRASIL, 2007, p. 44-45) ajuda a compreender isso quando afirma que:

\footnotetext{
Uma formação integrada, portanto, não somente possibilita o acesso a conhecimentos científicos, mas também promove a reflexão crítica sobre os padrões culturais que se constituem normas de conduta de um grupo social, assim como a apropriação de referências e tendências estéticas que se manifestam em tempos e espaços históricos, os quais expressam concepções, problemas, crises e potenciais de uma sociedade, que se vê traduzida ou questionada nas manifestações e obras artísticas.
}

Portanto, o trabalho educativo desenvolvido na escola necessita, de acordo com Gramsci (1968), buscar o equilíbrio entre a capacidade de operar manualmente (técnica e industrialmente) e a capacidade de pensar e de operar intelectualmente, e deve formar homens omnilaterais, que possam se inserir nas atividades sociais após terem sido elevados a certo grau de maturidade de criação intelectual e prática. Nesse sentido, a escola deve se apresentar como escola da cultura e trabalho, isto é, da ciência tornada produtiva e da prática tornada complexa, ou seja, com estreita relação com a vida coletiva. 
Outro documento oficial que regulamenta essa discussão é o Parecer $n^{\circ} 11 / 2012$, que precede as Diretrizes Curriculares Nacionais para a Educação Profissional Técnica de Nível Médio. De acordo com esse documento, "[...] a organização curricular deve fundamentar-se em metodologia interdisciplinar, que rompa com a fragmentação do conhecimento e a segmentação presentes na organização disciplinar tradicionalmente adotada de forma linear" (BRASIL, 2012, p. 47). Portanto, o parecer propõe que se rompa com o currículo escolar descontextualizado, distante do mundo experiencial de seus estudantes.

Na forma da lei das Diretrizes, os princípios norteadores da Educação Profissional Técnica de Nível Médio são, dentre outros:

a) relação e articulação entre a formação desenvolvida no Ensino Médio e a preparação para o exercício das profissões técnicas, visando à formação integral do estudante;

b) respeito aos valores estéticos, políticos e éticos da educação nacional, na perspectiva do desenvolvimento para a vida social e profissional;

c) trabalho como princípio educativo, com sua integração com a ciência, a tecnologia e a cultura como base da proposta político-pedagógica e do desenvolvimento curricular;

d) indissociabilidade entre educação e prática social, considerando-se a historicidade dos conhecimentos e dos sujeitos da aprendizagem;

e) indissociabilidade entre teoria e prática no processo de ensino-aprendizagem;

f) interdisciplinaridade assegurada no currículo e na prática pedagógica, visando à superação da fragmentação de conhecimentos e de segmentação da organização curricular;

g) contextualização, flexibilidade e interdisciplinaridade na utilização de estratégias educacionais favoráveis à compreensão de significados e à integração entre a teoria e a vivência da prática profissional, envolvendo as múltiplas dimensões do eixo tecnológico do curso e das ciências e tecnologias a ele vinculadas.

Esses princípios mostram-se em consonância com as ideias pelo coletivo de autores (CIAVATTA, 2005; RAMOS, 2005, MANACORDA, 1991; GRAMSCI, 1968) citados. Contudo, percebemos que temos um longo caminho para traçar no que se refere à implementação de tais prerrogativas. 


\section{DIÁLOGOS COM AS PESQUISAS SOBRE O ENSINO MÉDIO INTEGRADO}

Diante do que foi exposto podemos presumir que a implementação de Ensino Médio Integrado apresenta-se como um grande desafio tendo em vista que as condições materiais concretas, muitas vezes, não contribuíram com a sua efetivação. Na tentativa de compreender isso empiricamente propomos, nesta seção, um diálogo com as produções acadêmicas que abordaram a temática Ensino Médio Integrado com a intensão de entendermos como os estudiosos em nível de mestrado e doutorado tem se aproximado desse tema e realizado críticas a esse respeito. Para tanto, recorremos ao banco de teses e dissertações da Coordenação de Aperfeiçoamento de Pessoal de Nível Superior (Capes) e elencamos algumas pesquisas na área da educação.

Muitas foram as pesquisas encontradas ${ }^{3}$, porém, discutiremos apenas três, que nos permitirão realizar uma pequena amostragem do assunto. Uma delas foi a dissertação de Davanço (2008), que investiga como os professores e a equipe técnica têm feito a integração entre educação geral e Educação Profissional nas escolas públicas da rede estadual de ensino do Paraná. A autora entrevistou o corpo docente e a equipe pedagógica de uma escola selecionada. Procurou desvelar o que esses profissionais conheciam sobre os fundamentos teóricos e metodológicos da proposta e como procuravam fazer em suas atividades a integração entre a educação geral e a Educação Profissional. Ela percebe que o desconhecimento, por parte desses profissionais, dos fundamentos políticos e pedagógicos que norteiam a proposta do Ensino Médio Integrado os tem levado a uma atuação anacrônica em relação à proposição de integração dessa modalidade de Ensino Médio. Para Davanço (2008), é preciso investir na formação continuada de professores que oportunize o acesso aos conhecimentos mínimos necessários para fazer avançar no interior da escola um modelo de Educação Profissional pautado em novas bases.

Em consonância com a dissertação apresentada, está a tese de Coutinho (2011), que pretende analisar a precariedade, as limitações de alcance e as possibilidades do Decreto $n^{\circ}$ 5.154/2004, como caminho alternativo na construção de outra concepção educacional, na perspectiva de superação do modelo vigente de inspiração neoliberal. Nessa pesquisa, o autor reafirma que as discussões sobre o assunto são reincidentes, permeiam todos os anos, desde a promulgação do

\footnotetext{
${ }^{3}$ Para conhecer a Revisão de Literatura completa ver Chisté, 2013.
} 
Decreto $n^{\circ} 5.154 / 2004$. Permanece a intenção de investigar se a prática tem atendido aos reclames legais postos pela referida lei e também ao aporte teórico relacionado com a formação omnilateral fomentado pela tradição marxista. Nesse sentido, Coutinho posiciona-se de forma crítica, valoriza a formação do professor como agente de mudança capaz de pensar e construir coletivamente o ensino integrado na perspectiva politécnica.

Outro autor, nesse escopo de pesquisas, é Benfatti (2011) que pretende compreender também essa modalidade de Ensino Médio. Os resultados da investigação indicam que a integração está idealizada, mas desenvolve-se por práticas curriculares que ainda acompanham o modelo dualista no qual teoria e prática estão dissociadas e acontecem por meio de práticas curriculares isoladas e específicas de cada matéria, o que possibilita afirmar que a integração necessita de processos avaliativos que indiquem às escolas de Ensino Médio Integrado suas necessidades, suas dificuldades e as mudanças necessárias à efetivação da integração curricular proposta nos documentos do Ministério da Educação. A autora também acredita na necessidade de fomentar momentos de formação de professores para atenuar o desconhecimento dos aspectos legais e teóricos que abarcam o Ensino Médio Integrado.

A partir das constatações de Davanço (2008), Coutinho (2011) e Benfatti (2011), e do referencial teórico citado, é possível apontar algumas ações que precisam ser garantidas para atingir o Ensino Integrado, tais como:

a) definir o Ensino Médio Integrado como política pública no âmbito da educação, com ações efetivas que garantam o financiamento, a administração de recursos para o desenvolvimento de qualidade do Ensino Médio Integrado;

b) superar as bases curriculares que ainda não asseguraram os princípios do currículo integrado ciência, trabalho e cultura; ou seja, a superação da organização curricular dualista, que continua a dissociar o currículo do Ensino Médio do currículo da Educação Profissional e a dificultar a formação omnilateral;

c) considerar que até o momento as propostas de integração do Ensino Médio ao profissional não se efetivaram na prática; 
d) formular os currículos com bases concretas para a integração e articulação dos saberes, bem como para o desenvolvimento dos saberes de forma contextualizada, problematizada, inter e transdisciplinar, que superem a concepção fragmentada e dissociada do currículo à realidade, voltado apenas para as necessidades do mercado;

e) organizar o currículo a partir de ações e estratégias de participação colegiada e plenamente amparada pela formação contínua dos docentes para o currículo integrado;

f) considerar que, apesar dos desafios o Decreto $n^{\circ} 5.154 / 2004$ (incorporado a LDB $n^{\circ}$ 9.394/1996 por meio da Lei $\left.n^{\circ} 11.741 / 2008\right)$, foi um avanço em relação ao Decreto $n^{\circ}$ $2.208 / 97$.

Enfim, as pesquisas analisadas apontam falhas e desafios que se relacionam com o Ensino Médio Integrado. Contudo, consideramos incipientes os relatos de ações efetivadas a partir das constatações dos desafios que se tem que enfrentar para alcançar, em tese, um ensino integrado. Isso revela que é preciso partir dessas constatações e avançar um pouco mais, no que se refere às ações que precisam ser fomentadas, pois as constatações dos desafios impostos já foram realizadas. Pensamos que uma alternativa seria propor ações que se aproximem de uma educação humanizadora e que se distanciem da razão instrumental, posta na dicotomia do ensino técnico ou da educação integral do ser humano. Além disso, os apontamentos de Davanço (2008), Coutinho (2011) e Benfatti (2011) apresentam como alternativa para a superação dos desafios relacionados ao Ensino Médio Integrado a formação de professores. Esses autores fazem parte de um grupo de pesquisadores que, em seus mestrados, apresentaram os desafios desse campo de pesquisa. Contudo, cabe indicar ressalvas e reflexões sobre a formação de professores como uma forma de superar esses desafios. 


\section{CONSIDERAÇÕES FINAIS}

A partir do exposto, é possível presumir que, com a estrutura atual do Ensino Médio Integrado, atender a todas as prerrogativas legais e teóricas fica cada vez mais difícil, se não forem pensadas possibilidades de superação, por meio de políticas públicas e da reflexão do coletivo professores e demais profissionais. Uma sistematização que parta da integração dos conhecimentos na busca de proposições que acabem com a instrumentalização dos jovens e a sua preparação para o mercado de trabalho nos moldes tecnicistas. No plano pedagógico, esta proposta pressupõe a integração de todas as disciplinas, sem compartimentar o conhecimento.

Portanto, o trabalho educativo desenvolvido na escola necessita buscar o equilíbrio entre a capacidade de pensar e fazer. Deve formar sujeitos omnilaterais, que possam se inserir nas atividades sociais após terem sido elevados a certo grau de maturidade de criação intelectual e prática. A escola atual deve se apresentar como escola da cultura e trabalho, isto é, da ciência tornada produtiva e da prática, complexa, ou seja, com estreita relação com a vida coletiva.

Para tanto, as disciplinas do currículo tradicional devem passar por reestruturação, tendo em vista o ensino com base na realidade concreta. A escola deve propor o contato com a herança cultural e ser uma escola criadora, capaz de contribuir com o desenvolvimento da personalidade e autonomia do aluno. Uma escola cujo objetivo básico é desenvolver o alicerce cultural sólido e durável, capaz de acompanhar o indivíduo pela sua vida, útil às suas atividades de trabalho e de vida, independentemente da especificidade exercida.

Cabe colocar, também, nem sempre a experiência da sala de aula é suficiente para que o conhecimento seja apreciado de maneira libertadora e integrada. Por isso, existe a necessidade de se desenvolver outras ações que complementem/aprofundem as atividades realizadas em sala de aula, com a instituição e implementação de políticas e/ou projetos contínuos que ampliem, aprofundem e extrapolem as aulas. Um dos modos de se fazer isso pode ser pela via de projetos interdisciplinares. Projetos que tenham como participantes pessoas interessadas em aprofundar seus conhecimentos em outras áreas, com propostas que atendam aos interesses dos jovens por uma educação integral, para além de uma educação somente instrumentalizadora. 
Além disso, conforme foi apontado pelas pesquisas analisadas, cabe pensar que a formação de professores e demais profissionais da educação (pedagogos, diretores etc.) precisa acontecer como um modo de se refletir sobre os desafios da Educação Profissional brasileira e, mais especificamente, sobre o Ensino Médio Integrado. Para tanto, essa formação precisa ser realizada de modo emancipatório-político, ou seja, que proporcione ao professor a observação de suas ações práticas de forma crítica, relacionando-as com as teorias educacionais e aos aspectos históricos e legais que se apresentam na realidade concreta, e assim contribuir para a emancipação politica. Essa atividade reflexiva exige uma relação dialética entre teoria e prática, percebe no ambiente colaborativo entre colegas professores e pesquisadores as condições institucionais e político-sociais necessárias para se refletir sobre a prática numa visão mais ampla de mundo. Além disso, os participantes do curso, seja a equipe da instituição que fomenta o curso ou os próprios professores e demais profissionais devem se colocar como colaboradores, atuarem juntos na condução das discussões. Assim, todos participam da organização e gestão das atividades propostas para a formação. $\mathrm{O}$ foco de interesse nesses encontros é a discussão aprofundada sobre a problemática vivida pelos professores em seus contextos de ensino buscando uma visão ampliada sobre a conjuntura social e econômica em que se inscreve. O diálogo apoia-se em textos, artigos, leis, pareceres e livros sobre o assunto.

Porém, é preciso estar atento para não responsabilizar os sujeitos da formação pela mudança pretendida. Sabe-se que são limitadas as possibilidades de ação individual docente, pois muitas são as dimensões implicadas. "Pode-se incorrer no voluntarismo messiânico da ação bem-sucedida ou, o que é mais provável, no insucesso frustrante da ação malograda. Ambos os enredos contrariam uma situação política refletida, realista e efetivamente transformadora" (MIRANDA; RESENDE, 2006, p. 517). É preciso, portanto, engajar-se para que as discussões realizadas na formação sejam convertidas, para além da prática docente, ou seja, que visem a reivindicar por políticas públicas com finalidade de imprimir avanços no Ensino Médio Integrado. Como alerta Ramos (2005), faz-se necessário considerar que a realidade concreta é uma totalidade, síntese de múltiplas relações; um todo estruturado e dialético, do qual ou no qual um fato, ou conjunto de fatos, pode ser compreendido pela determinação das relações que os constituem. 


\section{REFERÊNCIAS}

BENFATTI, Xênia Diógenes. O currículo integrado do ensino médio integrado: da intenção à realização. 2011. Tese (Doutorado em Educação) - Universidade Federal do Ceará, Fortaleza, 2011.

BRASIL. Decreto $n^{\circ}$ 5.154, de 23 de julho de 2004. Regulamenta o $\S 20$ do art. 36 e os arts. 39 a 41 da Lei no 9.394, de 20 de dezembro de 1996, que estabelece as diretrizes e bases da educação nacional, e dá outras providências. 2004. Disponível em: <www.mec.org.br>. Acesso em: 10 jun. 2012.

Parecer CNE/CBE $n^{\circ}$ 39/2004. Aplicação do Decreto no 5.154/2004 na educação profissional técnica de nível médio e no ensino médio. 2004. Disponível em: <www.mec.org.br>. Acesso em: 10 jun. 2012.

. Lei $n^{\circ} 5.692$, de 11 de agosto de 1971 . Fixa diretrizes e bases para o ensino de $1^{\circ}$ e 20 graus, Brasília, DF, 1971. Disponível em: <www.mec.org.br>. Acesso: em 10 jun. 2012.

. Lei $\mathbf{n}^{\circ}$ 9.394, de 20 de Dezembro de 1996. Institui as diretrizes e bases da educação nacional. Brasília, DF, 1996. Disponível em: <www.mec.org.br>. Acesso: em 10 jun. 2012.

Parecer CNE/CBE $\mathbf{n}^{\circ} \mathbf{1 1 / 2 0 1 2}$. Aplicação das diretrizes curriculares nacionais para a educação profissional técnica de nível médio. 2012. Disponível em: <www.mec.org.br>. Acesso: em 10 jun. 2012.

Resolução $n^{\circ}$ 6, de 20 de setembro de 2012. Define diretrizes curriculares nacionais para a educação profissional técnica de nível médio. 2012. Disponível em: <www.mec.org.br>. Acesso em: 10 jun. 2012.

BRASIL/Ministério da Educação e Cultura/Secretaria de Ensino Técnico. Educação profissional técnica de nível médio integrada ao ensino técnico: documento-base. Brasília: 2007.

CIAVATTA, Maria. A formação integrada: a escola e o trabalho como lugares de memória e de identidade. In: FRIGOTTO, Gaudêncio; CIAVATTA, Maria; RAMOS, Marise (Org.). Ensino médio integrado: concepção e contradições. São Paulo: Cortez, 2005.

CHISTÉ, Priscila de Souza Chisté. Educação Estética na Educação Profissional: mediações das obras de arte de Raphael Samú. 2013. Tese (Doutorado em Educação) - Universidade Federal do Espírito Santo, Vitória, 2013.

COUTINHO, Wilson Carlos Rangel Coutinho. Neoliberalismo, política educacional e politecnia: tensões, contradições e possibilidades decorrentes do Decreto n. 5154/04. 2011. Tese (Doutorado em Educação) - Universidade do Estado do Rio de Janeiro, Rio de Janeiro, 2011.

DAVANÇO, Sandra Regina. A implantação do Ensino Médio integrado no Estado no Paraná: a difícil superação da cultura da dualidade. 2008. Dissertação (Mestrado em Educação) Universidade Federal do Paraná, Curitiba, 2008.

FRANCO, M. C. O trabalho como princípio educativo: uma concepção unificadora de ciência, técnica e ensino. In: BRASIL. Politecnia no ensino médio. São Paulo: Cortez, 1991.

FRIGOTTO, Gaudêncio; CIAVATTA, Maria; RAMOS, Marise (Org.). Ensino médio integrado: concepção e contradições. São Paulo: Cortez, 2005.

FRIGOTTO, Gaudêncio. Concepções e mudanças no mundo do trabalho e o Ensino Médio. In: FRIGOTTO, Gaudêncio; CIAVATTA, Maria; RAMOS, Marise (Org.). Ensino médio integrado: 
concepção e contradições. São Paulo: Cortez, 2005.

GRAMSCl, Antonio. Os intelectuais e a organização da cultura. Rio de Janeiro: Civilização Brasileira, 1968.

KUENZER, A. Pedagogia da fábrica: as relações de produção e a educação do trabalhador. São Paulo: Cortez, 1995.

MACHADO, Lucília R. de Souza. Politécnia, escola unitária e trabalho. São Paulo: Editora Cortez: Autores Associados, 1991.

MANACORDA, Mario Alighiero. Marx e a pedagogia moderna. São Paulo: Cortez: Autores Associados, 1991.

MARX, Karl. Manuscritos econômico-filosóficos. Tradução de Jesus Ranieri. São Paulo: Boitempo, 2004.

MARX, Karl. Manuscritos econômico-filosóficos. Tradução de Jesus Ranieri. São Paulo: Editora Martin Claret Ltda, 2001.

MOURA, Dante Henrique. Educação básica e Educação Profissional: dualidade histórica e perspectivas de integração. In: REUNIÃO ANUAL DA ASSOCIAÇÃO NACIONAL DE PÓS-GRADUAÇÃO E PESQUISA EM EDUCAÇÃO, 2005, Caxambu. Anais Eletrônicos. Disponível em: <http://www.anped.org.br/reunioes/30ra/trabalhos/GT09-3317--Int.pdf>. Acesso em: 10 jun. 2012.

RAMOS, Marise. Possibilidade e desafios na organização do currículo integrado. In: FRIGOTTO, Gaudêncio; CIAVATTA, Maria; RAMOS, Marise (Org.). Ensino médio integrado: concepção e contradições. São Paulo: Cortez, 2005.

RAMOS, Marise. A concepção do Ensino Médio integrado. Debate realizado no seminário promovido pela Secretaria de Educação do Estado do Pará nos dias 8 e 9 de maio de 2008. Disponível em: < http://tecnicadmiwj.files.wordpress.com/2008/09/texto-concepcao-do- ensinomedio-integrado-marise-ramos1.pdf>. Acesso em: 9 maio 2012.

SANTOS, Jailson Alves dos. A trajetória da educação profissional. In: VEIGA, Cynthia et al. 500 anos de educação no Brasil. Belo Horizonte: Autêntica, 2000. p. 205-224.

SAVIANI, Dermeval. Sobre a concepção de politecnia. Rio de Janeiro: Fiocruz, 2003.

Escola e democracia. São Paulo: Cortez e Autores Associados, 1989. 